\title{
Analysis of activity times in the process of a wooden box manufacturing
}

\author{
L. PUSZTAI ${ }^{1}$, B. KOCSI ${ }^{2}$, I. BUDAI ${ }^{3}$, L. NAGY ${ }^{4}$ \\ ${ }^{1}$ University of Debrecen, Faculty of Engineering, Department Engineering Management and Enterprises, \\ pusztai.laszlo@eng.unideb.hu \\ ${ }^{2}$ University of Debrecen, Faculty of Engineering, Department Engineering Management and Enterprises, \\ kocsi.balazs@inf.unideb.hu \\ ${ }^{3}$ University of Debrecen, Faculty of Engineering, Department Engineering Management and Enterprises, \\ budai.istvan@eng.unideb.hu \\ ${ }^{4}$ University of Debrecen, Faculty of Economics and Business, Department of Research Methodology and Statistics, \\ nagy.lajos@econ.unideb.hu
}

Abstract. The main target of companies is to earn money and achieve profit. In order to fulfil these needs, companies have to reduce their costs. Cost reduction is often associated with bad quality products, but it could be done in a different way. Sometimes it is enough to examine only their own processes and then benefit from the process optimization, process improvement or process scheduling. In this article a case study is presented, in which the differences in a production scheduling are evaluated with the application of Monte-Carlo simulation and descriptive statistics. At the end of the paper the most efficient material sequence is selected at the manufacturing company by using weighted sum model.

\section{Introduction}

Production management has a key role at all manufacturing companies. Their aim is to satisfy the customer needs within a required period of time and at the lowest possible cost. In order to achieve these goals, production processes must be well-organized and well-scheduled. However, the opposite outcome can be experienced, if the activity times of the different machines are not adjusted to one another, resulting a system collapse. It can lead to further problems in the production, such as the appearance of material waiting time and machine waiting time as well as the increase of total process time. None of these problems is good for the company, because in the case of material waiting time, work in process can appear between machines or workshops, the resulting extra inventory occupies space in the production area and means more costs for the company. In addition, this increased inventory hides problems in the production. The latter two problems cause a decrease in the effective capacity of the production, which can result in manufacturing fewer products in a given period of time. In this paper we aimed at presenting a case study on a wooden box manufacturing company, where the above mentioned indicators were measured and evaluated. 


\section{Theoretical background}

\subsection{Wastes in the production}

Production processes are complex systems, where output is created out of input trough a transformation process [1]. Such production processes are usually unique, they depend on the product type, as well as on the resources and the constraints of the company. However, there are common issues these companies have to deal with, for example, measuring the efficiency of their processes, and looking at how to achieve a higher level of efficiency [2]. The production process efficiency depends on many factors, but one important is the proportion of non-value added activities in a given process [3]. Non-value added activities (also known as wastes) require and use human, financial and other resources, however, these activities are not valuable and not paid by the customer [4]:

- Extra transportation: illogically large transportation distance between two workshops.

- Extra inventory: occupies production space, implies extra cost for the company, while it hides problems within the production process.

- Extra motion: an operator touches the product more times than it is necessary (e.g. left-right handed problem).

- Waiting time: when an operator or machine should work, but they have to wait for an information or input, etc.

- Over-processing: extra activity which is not requested by the customer.

- Overproduction: the company's inventory level will be higher, which is itself a kind of a waste.

- Defect: if a product is faulty, it must be corrected by sending it back into production.

Some of the wastes are closely linked to one another, like overproduction to inventory, waiting time to inventory [5]. Process improvement techniques, like Lean or Six Sigma, and other techniques, e.g. mathematical analyses could help to make a production system balanced, efficient and last but not least cost-effective [6].

\subsection{Monte-Carlo simulation}

A simulation model is a simplified mathematical representation of a real system, which imitates the system's behaviour. As opposed to the accurate results of analytical models, the simulation technique includes the operation and completion of the model in a particular time period, in order to provide representative samples of performance indicators [7]. Stochastic and deterministic models are differentiated. In deterministic models, randomness and probabilities are not included. The aim of the stochastic model is randomly select values on the basis of probability distribution assigned to uncertain factors, and to determine connections between variables [8]. Simulation is run between 1000 - 10000 times with the use of a computer, for example Microsoft Excel, R, Oracle Crystal Ball. 
DOI: 10.21791/IJEMS.2018.4.39.

After which, the expected values and their standard deviations can be calculated for the expected outcome variable. Outcome variables usually indicate income, costs, activity times and their risks.

There are more than 50 different probability distributions known in the world of science that can be applied in Monte-Carlo simulation. However, this great variety of distributions makes the practical usage of Monte-Carlo simulation complicated, therefore, the number of applied distributions are reduced.

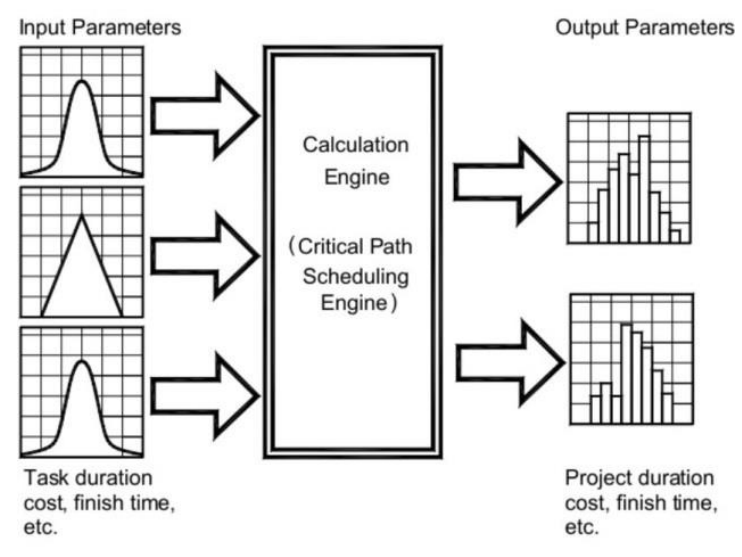

Figure 1: a schematic description of Monte-Carlo simulation

Normal-, triangular- and uniform probability distributions are the most common in industrial modelling, as seen in Figure 1 [7].

\subsection{Multi-criteria decision making}

Making decision is an everyday task for managers. To make justified decisions, the application of decision making methods is obligatory [9]. There are a lot of methods which can be used for quantitative data, such as Polano-method [10], Analytic Hierarchy Process [11], Promethee [12]. A simple but effective method is the weighted sum model [13]. This method can be used for the cases of more than one criterion, whose relative weights are different from one another:

$$
A_{i}=\sum a_{i j} w_{j}
$$

Where,

$A_{i}$ presents the calculated value of an alternative $i$,

$a_{i j}$ stands for the value of the alternative $i$ based on a criterion $j$,

$w_{i}$ is for the weight of the criterion $j$.

With the use of this method alternatives can be ranked by assigning weight to each criterion [13].

\section{Research methodology}

In this chapter, all the circumstances of the production and all the steps of the research are presented. 


\subsection{Product and process presentation}

The examined company deals with manufacturing and selling wooden boxes. The company manufactures high batches in product oriented layout, because these features are the most worthwhile for the company regarding raw material purchasing costs and production costs. All parts of these wooden boxes are made of the same raw material, therefore, the material flow sequence can be modified at the workshops. To make the steps of the evaluation easier, every part of the wooden box is assigned a value between 1 and 4 :

1 = wooden base panel, this material is used for making the bottom part (pallet) of the wooden box.

$2=$ wooden lath, this makes the box stronger.

$3=$ front panel, the side cover of the box.

$4=$ wooden top panel, this is the cover of the wooden box.

The production consists of the following 5 stages (each workshop is highlighted in different colour in Figure 2.):

- Pendulum sawing: in this stage, raw material is cut into the required length.

- Thickening plane: at this workshop, semi-processed wood is tailored to the proper thickness.

- Wood plane: in this activity, the wood is planed by a machine.

- Band sawing: the semi-processed material is cut into the required width.

- Assembling the wooden box. Every part of the box must be completed to finalize the activity.

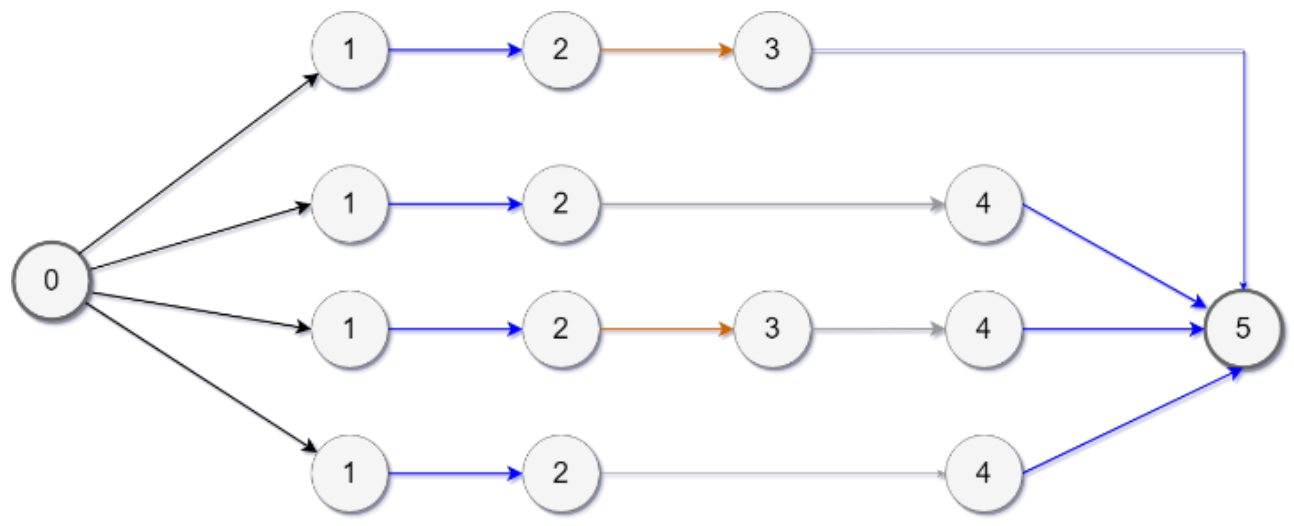

Figure 2: Production flowchart

\subsection{Steps of the research}

The first phase of the analysis was data collection. In this phase, the research group became familiar with the production process. The production flowchart was drawn up with the help of the operators. Followingly, time measurement was carried out during each process activity. 20 measurements were made in each workshop. These data served as the identification of probability distributions for each activity time. The next step of the research was the determination of the production rules. In this stage, 
the starting points of the production were calculated. Furthermore, material sequence, total process times, material and machine waiting times were all determined in this stage. In the third step, MonteCarlo simulation was run 10000 times, and its inputs were starting times, stochastic activity times, material and machine waiting times. These data served as a basis for further examinations. Eventually, the results generated by the simulation were evaluated by descriptive statistics. In the end, the best material sequence was chosen by weighted sum model.

\subsection{Rules for wooden box production}

The created rules were divided into two categories: the first category is valid for the first workshop, while the second set of rules is applicable to all the other workshops.

First workshop: By using the raw material arriving first in the sequence, production is started at the $0^{\text {th }}$ point of time. This task is finished when the process activity time expires. The next raw material arriving in the sequence continues production when the processing of the previous material is finished.

Other workshops: A semi-processed product can only start to be processed in a workshop, if the following conditions are fulfilled:

- The semi-processed product is completed in the previous workshop,

- The current workshop is available and ready for production.

When these conditions are not fulfilled, either the material or the machine has to wait (both cannot occur at the same time in a given workshop). When the previous workshop already finished its production on its loaded material, however, the next workshop is still working on its loaded material, it is called material waiting. Machine waiting time occurs when the machine or workshop has completed the previous material processing activity, but the next material in the sequence is still being processed in the previous workshop.

\subsection{Applied methods and software applications}

Microsoft Excel was applied to model the previously determined rules in all the workshops, and to execute Monte-Carlo simulation. The results were input into R software in order to carry out both descriptive- and advanced statistical analyses as well as to visualize data.

\section{Results}

\subsection{Total Process times}

As far as this production is concerned, there can be 24 different material sequences in the production. The higher total process time a material sequence has, the worse it is for the company, because it induces a decrease in the effective capacity of machines. As Figure 2. depicts, there are huge differences in the total process times in material sequences. 


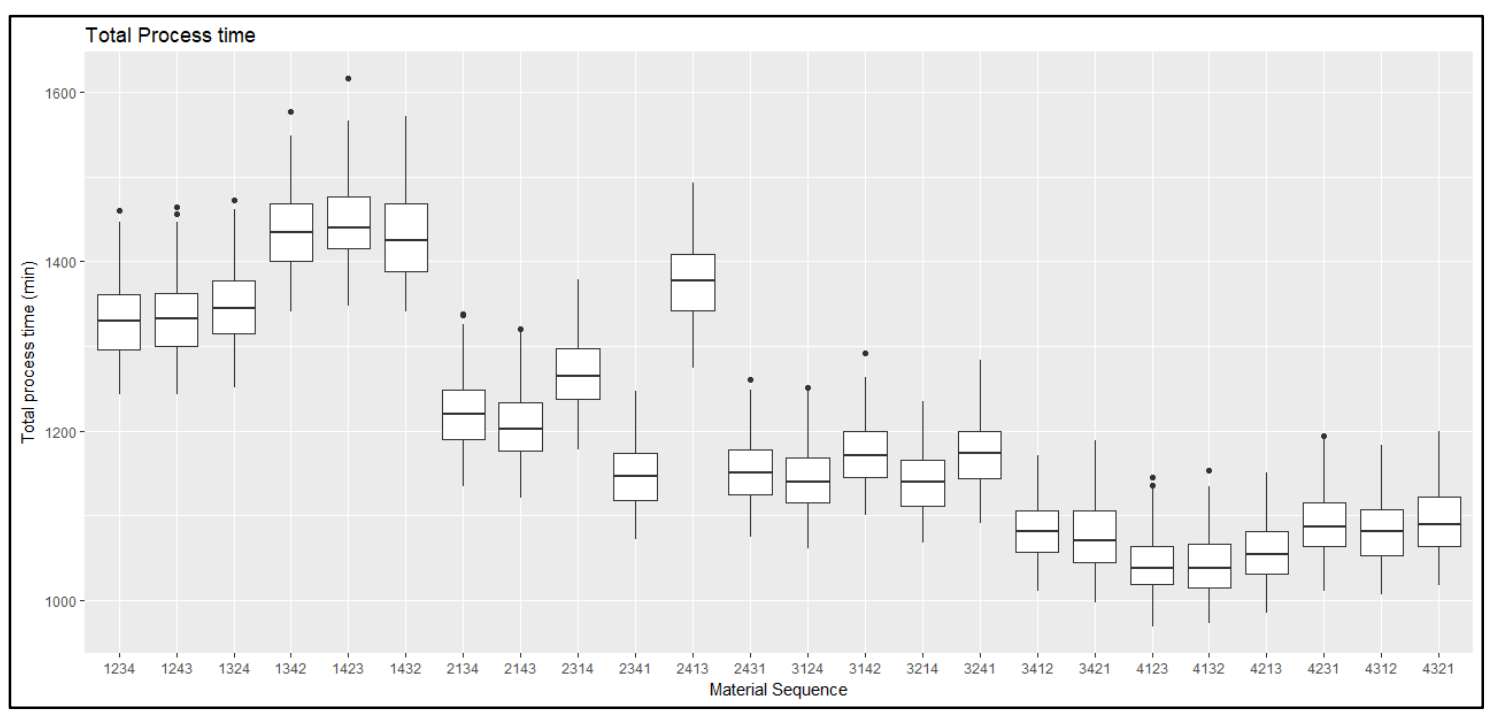

Figure 3: Total process times

The 1-4-2-3 material sequence provides the highest TPT value, while 4-1-2-3 has the lowest value. The difference between the medians of these two extreme values is more than 400 minutes, which equals almost 7 working hours per batch. In other words: in the former sequence 500 boxes can be produced in a given time, while in the latter sequences 700 boxes can be manufactured.

\subsection{Material waiting times}

When the workshop cycle times are not adjusted, inventory can accumulate between two workshops. It occurs when a semi-processed product is already completed in the previous workshop, but the next workshop is still working on its loaded material, the already completed parts must wait for processing. In this case study, the average material waiting times are between 1500 and 3000 minutes. These times are the sum of the material waiting times, measured in all workshops and added up.

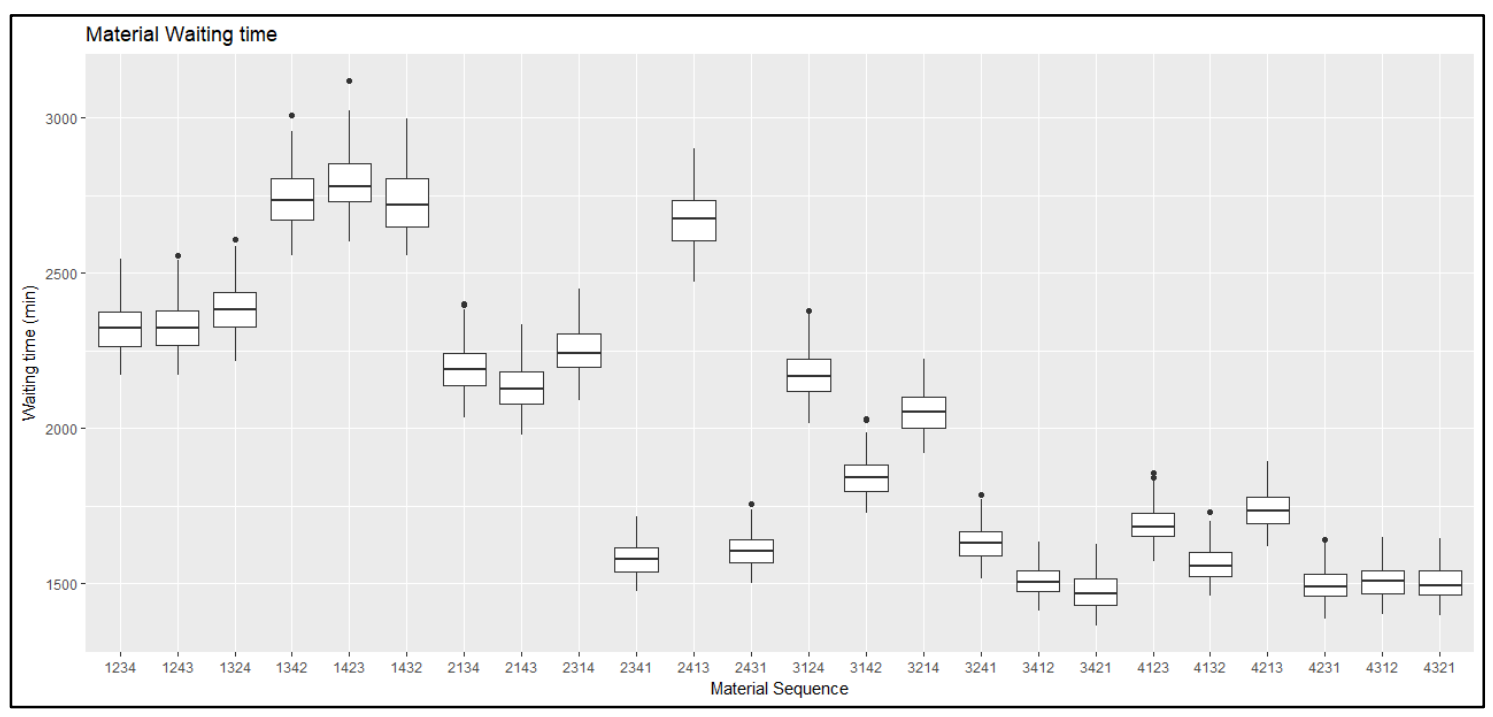

Figure 4: Material waiting times 
DOI: 10.21791/IJEMS.2018.4.39.

Too much waiting time means a lot of problems for the company. If a company schedules its production repeatedly, it will lead to a lot of inventory that cannot be handled by the operators. In addition, a lot of space will be occupied, which results in a lot of waste and the need for a bigger warehouse. Twice as much waiting time as the total process time is unacceptable, so in this case the most important aim of the company must be the reduction of material waiting times between the workshops by purchasing new machines and hiring new operators to balance the line. This kind of investments can also induce a decrease in the total process time.

\subsection{Machine waiting times}

Machines have to wait for the raw material when they have already finished the production of the loaded material, but the next semi-processed product to be loaded is still under process in the previous workshop.

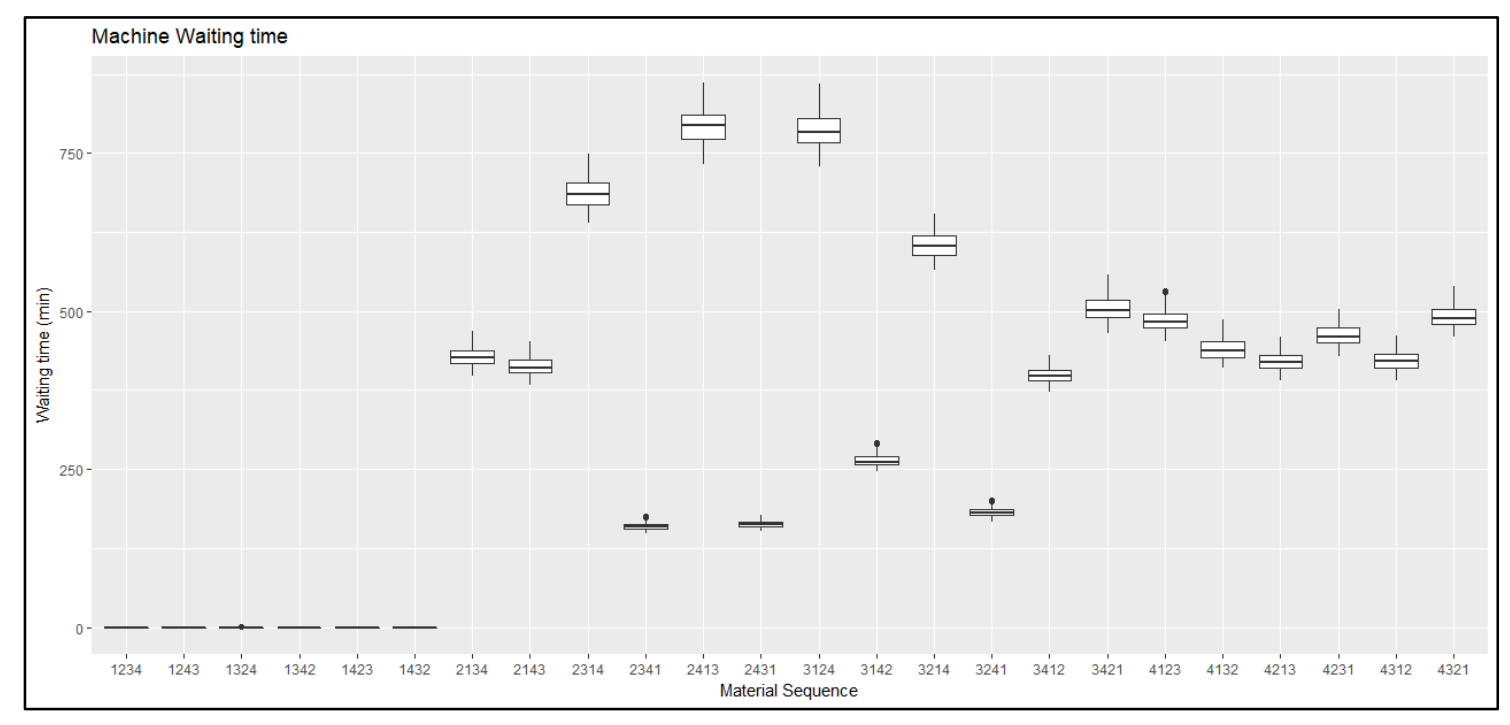

Figure 5: Machine waiting times

Machine waiting time also occurs when the production line is not balanced, and this kind of waste results in a decrease in the effective capacity of machines, that is, the machine could work, but it cannot, because there is no input for it. Furthermore, when there is no time for an operator or a machine to take a break, they are more likely to produce faulty products. For example, those sequences which start with "Material 1" provide the longest total process times while their machines are working all the time. On the other hand, during the waiting times of the machines, preventive maintenance or new setups can be implemented. In the case study, material sequences start with "Material 4", and they have the lowest total process times, while their machines can be stopped for approximately 500 minutes. The aim in this case is to find the balance between the working times and breaks during production. 


\subsection{Choosing the best material sequence}

In order to choose the best material sequence for the company, a decision making method was applied. A pre-selection was done in accordance with the requirements of the company. The constraint for the median of the total process time (TPT) was below 1200 minutes. In the case of material waiting, the median of material waiting times must be under 2000 minutes. Regarding machine waiting times, too low (under 100 minutes) and too high values (above 500 minutes) were excluded from further examinations.

\begin{tabular}{|l|c|c|c|c|c|c|c|}
\hline SEQ. & $3-1-4-2$ & $4-1-2-3$ & $4-1-3-2$ & $4-2-1-3$ & $4-2-3-1$ & $4-3-1-2$ & $4-3-2-1$ \\
\hline Median of TPT (min) & 1171 & 1038 & 1038 & 1053,5 & 1086 & 1081,5 & 1089,5 \\
\hline Median of Mat. w. (min) & 1840 & 1683 & 1558 & 1733 & 1491 & 1506,5 & 1495 \\
\hline Median of Mac. w. (min) & 262 & 483 & 438 & 419 & 460 & 421 & 489 \\
\hline
\end{tabular}

Table 1: Basic data for weighted sum model

By applying these constraints, 17 material sequences were excluded, and 7 sequences were included and then evaluated. The next step was to normalize all the data for further calculations. For all indicators, the lower value is the better value, so the following formula was applied for the data:

$$
a_{i j}=\frac{\min a_{i j}}{a_{i j}}
$$

The next step was to assign weights. The company did not provide any information about their exact preferences, so the research team was asked to assign weights to criteria in order to achieve minimum deviations from each goal, such as in multi-objective linear programming:

Variables:

$$
w_{j}
$$

Where w stands for weights on criteria $j$

Objective:

$$
\min \left(\max \left(a_{i j} w_{j}\right)\right)
$$

$a_{i j}$ stands for the value of the alternative $i$ based on a criterion $j$,

$w_{i}$ is for the weight of the criterion $j$. 
DOI: 10.21791/IJEMS.2018.4.39.

The aim of the calculation was to determine weights, by which the minimum deviation from goals can be achieved.

\begin{tabular}{|l|c|c|c|c|c|c|c|c|}
\hline SEQ. & Weight & $\mathbf{3 - 1 - 4 - 2}$ & $4-1-2-3$ & $4-1-3-2$ & $4-2-1-3$ & $4-2-3-1$ & $4-3-1-2$ & $4-3-2-1$ \\
\hline Median of TPT (min) & 0,3115 & $\mathbf{0 , 8 9 0}$ & 1,000 & 1,000 & 0,990 & 0,960 & 0,960 & 0,950 \\
\hline Median of Mat. w. (min) & 0,3115 & $\mathbf{0 , 8 1 0}$ & 0,890 & 0,960 & 0,860 & 1,000 & 0,990 & 1,000 \\
\hline Median of Mac. w. (min) & 0,3770 & $\mathbf{1 , 0 0 0}$ & 0,542 & 0,598 & 0,625 & 0,570 & 0,622 & 0,536 \\
\hline Sum / Final value & 1,000 & $\mathbf{0 , 9 0 7}$ & 0,793 & 0,836 & 0,812 & 0,825 & 0,842 & 0,809 \\
\hline
\end{tabular}

Table 2: Weighted sum model

According to the results of the weighted sum model, the best material sequence is 3-1-4-2 for the company. The second sequence has almost the same result (4-3-1-2). If a company would like to reduce its total process time by 89.5 minutes, and aims to reduce material waiting time by 333.5 minutes, it is possible at the cost of an extra 179-minute machine waiting time. The third sequence (31-4-2) has the best machine waiting time, but in the cases of the other indicators it performed the worst. The next sequence is the 4-1-3-2 that has one of the best TPT-s, but the difference between material waiting times compared to the first sequence is very significant, as it comes to more than 282 minutes.

\section{Conclusion}

In this article a case study on determining and evaluating the best material sequence with the use of Monte-Carlo simulation, descriptive statistics and multi-criteria decision making method was described. The basis of these calculations consists of three important indicators in production management: total process time, material waiting time and machine waiting time. The targets were contradictory in this case study: one indicator could not be optimized simultaneously with other indicators due to the unbalanced production line. However, if a company is aware of these indicators, it can effectively schedule its production in accordance with the aims.

\section{Acknowledgement}

This research was supported by the NTP-NFTÖ-17-B-0509 project. The project was financed by the Hungarian Ministry of Human Capacities and the Human Capacities Grant Management Office.

\section{References}

[1] Russel - Taylor, Operations Management, Wiley \& Sons Inc. 226-256.

[2] IFUA Horváth \& Partners, Folyamatmenedzsment a gyakorlatban, IFUA Horváth \& Partners,

[3] James P. Womack, Daniel T. Jones, Lean thinking, Free Press, 17-274.

[4] Kosztolányi János, Schwahofer Gábor, Lean szótár, 17-22. 
[5] Productivity Press Development Team, Kanban for the shopfloor, 1-28.

[6] Michael L. George, The lean six sigma pocket toolbook, McGraw-Hill Companies, 1-26.

[7] Wayne L. Winston. Operations Research: Applications and Algorithm, Brook/Cole,

[8] Weihua Y., Cong T., Monte-Carlo simulation of information system project performance, System Engineering Procedia, 340-345.

[9] Zoltayné Paprika Zita: Döntéselmélet, Üzleti Szakkönyvtár, 255-301.

[10] Rapcsák Tamás, Többszempontú döntési problémák, MTA SZTAKI, 11-12.

[11] Thomas L. Saaty, Decision making with the analytic hierarchy process, International Journal of Services Sciences, 83-98.

[12] Jean-Pierre Brans, Bertrand Mareschal, Promethee Methods In Multiple Criteria Decision Analysis: State of the Art Surveys, Springer, 187-221.

[13] Triantaphyllou E., Multi-Criteria Decision making: A comparative case study, 6-9. 